\title{
Application of Inorganic Ceramic Membrane in Wastewater Treatment: Membrane Fouling Control and Cleaning Procedure
}

\author{
Yanjie Wei \\ Key Laboratory of Environmental Protection in Water Transport Engineering Ministry of Communications, Tianjin Research Institute of \\ Water Transport Engineering, Tianjin 300456, China
}

\begin{abstract}
Using the inorganic ceramic membrane equipment for wastewater treatment, the transit membrane pressure (TMP) raises with membrane fouling, interception efficiency declines, and operation energy consumption increases. These issues have been the main problems to be solved in the technology development of inorganic ceramic membrane. Thus, it is necessary to analyze the membrane fouling process and formation mechanism, as well as propose strategy for retarding membrane fouling. Formation mechanism, control measures and cleaning procedure of membrane fouling were discussed in this paper, so as to provide evidence or reference for further popularization and application of inorganic ceramic membrane in wastewater treatment
\end{abstract}

\section{Introduction}

Inorganic ceramic membrane has the advantages of high temperature resistance, high acid and alkali resistance, homogenous pore-size distribution, steady chemical property, high strength, large flux, long lifetime, antipollution, simple structure, small floor area, few matching equipment, easy installation, no chemical additives, high operating efficiency, high management and automation, and so on. Thus, this technology has been applied in the wastewater treatment of food industry, biochemical engineering, petrochemical industry, mechanical metallurgy. However, the transit membrane pressure (TMP) raises with membrane fouling, interception efficiency declines, and operation energy consumption increases. These issues have been the main problems to be solved in the technology development of inorganic ceramic membrane. Thus, it is necessary to analyze the membrane fouling process and formation mechanism, as well as propose strategy for retarding membrane fouling.

\section{Membrane fouling process}

Membrane fouling processes contain the main stages during the application of inorganic ceramic membrane in wastewater treatment. [1]

(A) Initial stages, oil drops with the diameter smaller than membrane pore size, directly enter into the permeate liquid after passing the membrane. This stage lasts tens seconds or a few mintues.

(B) When passing the membrane pore, the oil drops would adsorp or attach on the inner surface due to the electrostatic force and affinity. At the same time, oil drops with the same size with membrane pore size, block the membrane pore, resulting in the reducing of effective cross section area, and the flux decreases greatly.

(C) When the oil drops adsorption saturates the oil drops would adsorp or attach on the surface between pores.

(D) With the enrichment of oil drops attached on the surface between pores, oil drops link together with bridging and become oil layer covering the membrane, resulting in severe blocking.

\section{Research on Membrane Fouling Control}

\subsection{Improvement of membrane properties}

With the prefection of chemical compositon, stability and hydrophilicity of membrane can be improved, filtration performance could be optimized, and operation energy consumption could be reduced.

In the research by Faibish, the inorganic ceramic membrane was used for treatment of alkane-oilwastewater, it was found that the flux increased by $20 \%$ after surface modification [2, 3]. Shen, et al [4] used Burden- $a$ for surface modification of inorganic ceramic membrane treating some decarburizing solution, and membrane fouling was significantly slowed down. The membrane pore blocking was also relieved. High and stable flux was finial reached with the solid impurity remove efficiency of $94.5 \%$. Hu, et al [5] utilized $\alpha$ $\mathrm{Al}_{2} \mathrm{O}_{3}$-microfiltration membrane with the pore size of 0.2 $\mu \mathrm{m}$ to treat simulated oily wastewater. The flux was 166.7 L/ $\left(\mathrm{m}^{2} \cdot \mathrm{h}\right)$. After $\mathrm{TiO}_{2}$ - nano-modification, the flux increased to $192.6 \mathrm{~L} /\left(\mathrm{m}^{2} \cdot \mathrm{h}\right)$. The membrane has better antifouling and acid/alkaline resistance properties. Furthermore, the mechanism of the increase of the modified membrane permeate flux is discussed initially in terms of the hydrophobicity or hydrophobicity and zeta potential of the modified membrane surface.

\subsection{Coupling with other treatment process}

In view of the complicated composition and difference of site conditions, any single wastewater treatment procedures can not satisfy the processing demands. Hence, inorganic ceramic membrane also should be coupling with other treatment process, for further improving the filtration role of membrane.

Wang et al [6] used the $\mathrm{ZrO}_{2}$-microfiltration membrane for rolling emulsion treatment. The flux and 
remove efficiency of membrane could be improved significantly, when the raw wastewater was pre-treated. The flux and oil remove efficiency reached $80 \mathrm{~L} /\left(\mathrm{m}^{2} \cdot \mathrm{h}\right)$ and $99.9 \%$, respectively. Zhao, et al [7] utilized ceramic membrane combined with adsorption by magnesium hydroxide to treat active dye wastewater. The membrane pore size was $1.0 \mu \mathrm{m}$, magnesium salt dosage was 600 $800 \mathrm{mg} / \mathrm{L}$, pH was $11-12$, operating pressure was $0.15 \mathrm{Mpa}$, cross-flow velocity was $3-5 \mathrm{~m} / \mathrm{s}$, the decolorizing rate of the combined technology was above $98 \%$, membrane flux stabliized at $150 \mathrm{~L} /(\mathrm{m} 2 \cdot \mathrm{h})$. Zhang et al [8] used coagulation and ceramic membrane filtration for the treatment of cathodic electrocoating wastewater. With the $\mathrm{pH}$ of 6.7 , the zirconia membrane pore size of $0.2 \mu \mathrm{m}$, crossflow velocity of $4.2 \mathrm{~m} / \mathrm{s}$, operating pressure of $0.15 \mathrm{Mpa}$, tempeture of $30^{\circ} \mathrm{C}$, membrane flux was 250 $\mathrm{L} /\left(\mathrm{m}^{2} \cdot \mathrm{h}\right), \mathrm{COD}_{\mathrm{Cr}}$ remove efficiency of coagulation stage was $63 \%$, the one of combined process reached $85 \%$. Penetrant could be recycled.

Ren et al [9] utilized ceramic ultrafiltration membrane/biological contact oxidation technology to treat oily wastewater from steel cold rolling; the outlet quality could satisfy the requirement for miscellaneous domestic water quality standard. All of the wastewater, waste oil and residue could be recycled. Yao et al [10] used polyacrylic acid to assist the $\mathrm{Cu}^{2+}$ - wastewater treatment by ceramic membrane. When $\mathrm{pH}$ was beteween 5-6.3, the $\mathrm{Cu}^{2+}$ remove efficiency of all of the $200 \mathrm{~nm}-, 50 \mathrm{~nm}$ - and $20 \mathrm{~nm}$ ceramic membrane was more than $99.8 \%$, with the flux exceeding $140 \mathrm{~L} /\left(\mathrm{m}^{2} \cdot \mathrm{h}\right)$. Shu et al [11] investigated the role of ultrasonic in the ceramic membrane filtiration process. When the ultrasonic power was $8 \mathrm{~W}$, the insertion depth of ultrasonic probe into the membrane tube was $7 \mathrm{~cm}$, the flux increased from initial $70 \mathrm{~L} /\left(\mathrm{m}^{2} \cdot \mathrm{h}\right)$ to $210 \mathrm{~L} /\left(\mathrm{m}^{2} \cdot \mathrm{h}\right)$. The pollutant removal efficiency was above $99.9 \%$.

$\mathrm{Xu}$ et al [12] used CMBR (ceramic membrane bio reactor) with carrier for municipal wastewater treatment, and studied the effects of different membrane pore size and carriers on flux and water quality. The results showed that f lux was between $110-150 \mathrm{~L} /\left(\mathrm{m}^{2} \cdot \mathrm{h}\right)(p=0.1 \mathrm{MPa}$, $V=2.8 \mathrm{~m} / \mathrm{s}$ ), and the system was capable of achieving over $90 \%$ COD removal performance. Ceramic particle filter and ceramic membrane reactor for advanced treatment were applied to treat the wastewater from a cough syrup medicine plant [13]. 1 - $2 \mathrm{~mm}$ diameter of ceramic particle and $2-3 \mu \mathrm{m}$ permeation diameter of ceramic membrane were used. The BOD, COD, SS and $\mathrm{NH}_{4}{ }^{+}-\mathrm{N}$ of the effluent finally meet the discharge standard of wastewater. Zhang et al [14] used organoclay as aid for ceramic membrane microfiltration of oily wastewater to improve the removal efficiencies of oils, to mitigate the membrane fouling. The results showed that the permeate flux was $60 \%$ greater than that organoclay was not used, and the flux was $240 \mathrm{~L} /\left(\mathrm{m}^{2} \cdot \mathrm{h}\right)$ at transmembrane pressure of $0.10 \mathrm{MPa}$, cross-flow velocity of $5 \mathrm{~m} / \mathrm{s}$, and tempeture of $30^{\circ} \mathrm{C}$. In addition, the removal of oils was improved, and the concentration of oils was less than $10 \mathrm{mg} / \mathrm{L}$, the permeate can be reused under very safe conditions. Du et al [15] utilized polyacrylic acid sodium with relative molecular mass 300000,1000000 , or 5000000 as complex agent to treat the simulated oily and low-content radioactive wastewater. Results show that under various conditions, the highest interception rates of oil, $\mathrm{Fe}^{3+}, \mathrm{Mn}^{2+}, \mathrm{Ni}^{2+}$, and $\mathrm{Co}^{2+}$ by ceramic membranes were around $100 \%, 100 \%, 100 \%, 98.11 \%$ and $100 \%$ respectively. It is feasible for polymer-assisted ceramic membrane to treat simulated oily and lowcontent radioactive wastewater. Pan et al [16] studied the application of inorganic ceramic membrane microfiltration coupled with ultrasonic to refine Bitong medicinal liquor. The results showed that continuous ultrasound could significantly enhance the membrane permeability, permeation flux was improved as high as $173 \mathrm{~L} /\left(\mathrm{m}^{2} \mathrm{~h}\right)$, with the incresing rate of flux $31.6 \%$. Meantime, continuous ultrasound could effectively reduce membrane filtration resistance, particularly the resistance through deposition on the membrane surface layer, with a decrease rate more than $50 \%$. Within a certain range, the enhance effect of ultrasound on the membrane process had a positive correlation against operating pressure and a negative correlation against the operating temperature. Thus, it could be concluded that ceramic membrane microfiltration with on-line coupling with ultrasonic technique is a safe and effective mean of membrane separation

\subsection{Improving flow regime, alleviating the attachment and sedimentary of pollutants}

It is necessary to enhance the turbulent extent on the membrane surface, so as to alleviate the attachment and sedimentary of pollutants, and improve the permeate flux.

Shen, et al [17] investigated the role of turbulence promoter on the performance of membrane separation of $\mathrm{CaCO}_{3}$ suspension with a 19-channel ceramic membrane. The appropriate types and structural parameters of turbulence promoter were obtained, and the flux increased by $23.76 \%$ (shown in Figure 1).

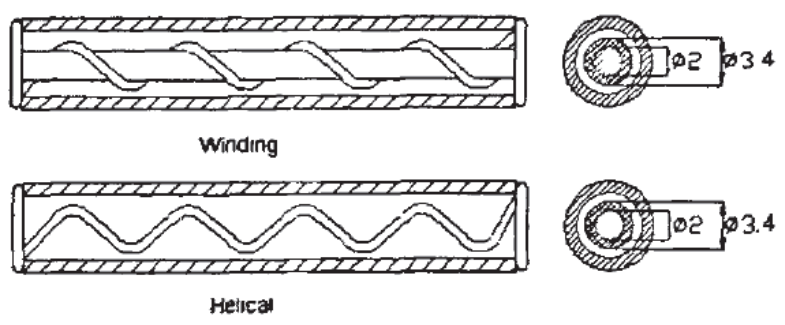

Figure 1. Turbulence promoter on the performance of membrane separation [12].

\section{Research on cleaning procedure of polluted ceramic membrane}

Generally, membrane fouling should be cleaned when the flux less than $30 \mathrm{~L} /\left(\mathrm{m}^{2} \cdot \mathrm{h}\right)$. Appropriate agent and procedure should be selected for fouling removal. There are mainly two kinds of cleaning methods: 
(1) Physical method contains high pressure water washing, backwashing and mechanical scrubbing with sponge balls.

(2) In chemical method, diluted alkali and acid, enzyme, surfactant, complexing agent and oxidant are usually used for membrane cleaning.

Shen et al [18] utilized ceramic membrane to treat suspension of microzyme, and studied the cleaning procedure of polluted ceramic membrane. It was found that the flux could be recovered $66.32 \%$ of the original value, when the cleaning procedure of $2 \% \mathrm{NaClO}-30 \mathrm{~min}$ and $2 \% \mathrm{HNO}_{3}-10 \mathrm{~min}$ was used under the condition of $25^{\circ} \mathrm{C}$ and $0.10 \mathrm{Mpa}$. While, the flux could be recovered $73.17 \%$ of the original value, using the cleaning procedure of $2 \% \mathrm{Ca}(\mathrm{OH})_{2}-30 \mathrm{~min}$ and $1 \% \mathrm{H}_{2} \mathrm{C}_{2} \mathrm{O}_{4}-10 \mathrm{~min}$ was used under the condition of $15^{\circ} \mathrm{C}$ and $0.15 \mathrm{Mpa}$. Wang et al [19] investigated the filtration performance of ceramic membrane treating cephenlosprin $\mathrm{C}$ fermentation liquor. The results showed that the flux could be recovered over $90 \%$ of the original value using the cleaning procedure of clear water washing-alkali washing- clear water washing-acid picking- clear water washing.

Wang et al [20] utilized ceramic membrane to treat waste emulsion, and used the procedure of alkali washing -acid picking alternatively clean the polluted ceramic membrane. The flux of $0.05 \mu \mathrm{m}$ ceramic membrane decreased to $100 \mathrm{~L} /\left(\mathrm{m}^{2} \cdot \mathrm{h}\right)$ in $6 \mathrm{~h}$. While, it could be recoverd to $630 \sim 680 \mathrm{~L} /\left(\mathrm{m}^{2} \cdot \mathrm{h}\right)$ using the cleaning procedure about three times, under the conditions of $0.1 \mathrm{Mpa}$ of operating pressure, and $60{ }^{\circ} \mathrm{C}$ of temperature. Wang el al [21] used ceramic membrane to treat oily wastewater, and found that the membrane flux could be $96.2 \%$ of the orignial value, using the optimum procedure of $1.0 \% \mathrm{C}_{18} \mathrm{H}_{29} \mathrm{O}_{3} \mathrm{SNa}-5 \mathrm{~min}, 1.5 \% \mathrm{NaOH}-15 \mathrm{~min}, 2.0 \%$ $\mathrm{HNO}_{3}-10 \mathrm{~min}$. $\mathrm{Gu}$ et al [22] studied the cleaning process of ceramic membranes treating emulsified suspension. The results showed that the optimal physical cleaning at room temperature could restore the membrane's standard permeability to higher than $96 \%$ of the original permeability. In the post-treatment process, permeation flux was not affected by cleaning agent concentration, but the cleaning process must be operated at a high flow rate. $\mathrm{Mu}$ et al [23] carried out a test for separation characteristics of bathing wastewater by ceramic nanofiltration. The method of membrane cleaning was preliminarily studied. The results showed that the ceramic nanofiltration membrane could remove COD, TOC, and turbidity of the bathing wastewater effectively, and washing the membarane with water, $\mathrm{NaOH}$ and $\mathrm{HNO}_{3}$ as cleaning agent could achieve better effect in this test.

\section{Conclusions and Prospects}

Ceramic membrane technology has become one of the most important technologies treating oily wastewater. However, it is hard to be applied in actual projects, due to its shortages of high cost, great investment, poor stainresistant capacity, and high energy consumption. Researchers have utilized different methods to overcome these problems, concluding Optimized structural design, adding turbulence promoter, and coupling with other treating processes. While, membrane fouling is still the most difficult problem to solve. Thus, it is necessary to enriched the theoretical aspects of ceramic membrane process by investigating the membrane fouling control and cleaning procedure.

\section{References}

[1] Gao B. Naning Universtiy of Technology (2003).

[2] Faibish R.S., Cohen Y. Colloids and Surfaces APhysicochemical and Engineering Aspects, 191: 2740 (2001).

[3] Faibish R.S., Cohen Y. Journal of Membrane Science, 182: 129-143 (2011).

[4] Shen H.Y., Liu Y.Z., Yan Z.G., et al. Modern Chemical Industry, 29: 74-76 (2009).

[5] Hu X.B., Zhou J.E., Wang Y.Q., et al. Journal of the Chinese Cermic Society, 38: 1900-1904 (2010).

[6] Wang P., Xu N.P., Shi J. Journal of Membrane Science, 173: 159-166 (2000).

[7] Zhao Y.J., Ji M., Zhang Y., et al. Membrane Science and Technology, 20: 41-45 (2000).

[8] Zhang J., Dong Q., Sun Y.X., et al. Membrane Science and Technology, 26: 57-60 (2006).

[9] Ren F.L. China Water and Wastewater, 24: 80-82 (2008).

[10] Yao C.M., Fan Y.Q. Membrane Science and Technology, 29: 79-82 (2009).

[11] Shu L., Xing W.H., Xu N.P. Chinese Journal of Chemical and Engineering, 15: 855-860(2007).

[12]Xu N., Xing W.H., Xu N.P. Membrane Science and Technology, 22: 65-68 (2002).

[13]Zhang C.H., Zhu S.Q., Qi L., et al. Chinese Journal of Environmental Engineering, 2: 1066-1068 (2008).

[14]Zhang J., Guo G.Y. Technology of Water Treatment, 36: 88-91 (2010).

[15]Du Z.H., Jia M.C., Wang X.W., et al. Industrial Water Treatment, 7: 60-63 (2011)

[16]Pan L.H., Huang M.Y., Guo L.W. Chinese Traditional and Herbal Drugs, 41: 1631-1634 (2010)

[17] Shen Z.X., Chen Y.Z., Cui P. Chemical Reaction Engineering and Technology, 26: 92-96 (2010).

[18] Shen L.M., Jin J.M., Chen Y. Journal of Naning University of Technology, 24: 74-77 (2002).

[19] Wang L.Y., Yang G., Xing W.H., et al. Journal of Chemical Engineering of Chinese Universities, 21: 604-607 (2007).

[20]Wang J.R., Wang X.S., Qiu Z., et al. Water Purfication Technology, 28: 32-34 (2009).

[21] Wang C.J., Chu L., Jin J. Technology of Water Treatment, 36: 52-55 (2010).

[22] Gu L., Liu Y.Z., Shen H.Y., et al. Chemical Industry and Engineering Progress, 26: 226-229 (2007).

[23] Mu X.F., Chen H.S., Bai Q.Z., et al. Technology of Water Treatment, 32: 52-54 (2007). 